Article

\title{
Confucius and Herding Behaviour in the Stock Markets in China and Taiwan
}

\author{
Batmunkh John Munkh-Ulzii ${ }^{1}\left(\mathbb{D}\right.$, Michael McAleer ${ }^{2,3,4,5,6, *}$, Massoud Moslehpour ${ }^{7}(\mathbb{D}$ and \\ Wing-Keung Wong ${ }^{2}$ (D) \\ 1 Department of International Relations, National University of Mongolia, Ulaanbaatar 14200, Mongolia; \\ ulzii03@gmail.com \\ 2 Department of Finance, Asia University, Taichung 41354, Taiwan; wong@asia.edu.tw \\ 3 Discipline of Business Analytics, University of Sydney Business School, Sydney, NSW 2006, Australia \\ 4 Econometric Institute, Erasmus School of Economics, Erasmus University Rotterdam, \\ 3000 Rotterdam, The Netherlands \\ 5 Department of Economic Analysis and ICAE, Complutense University of Madrid, 28040 Madrid, Spain \\ 6 Institute of Advanced Sciences, Yokohama National University, Yokohama 240-8501, Japan \\ 7 Department of Business Administration, Asia University, Taichung 41354, Taiwan; writetodrm@gmail.com \\ * Correspondence: michael.mcaleer@gmail.com; Tel.: +886-04-2332-3456 (ext. 1837)
}

Received: 20 October 2018; Accepted: 21 November 2018; Published: 26 November 2018

\begin{abstract}
It has been argued in the literature that financial markets with a Confucian background tend to exhibit herding behaviour, or correlated behavioural patterns in individuals. This paper applies the return dispersion model to investigate financial herding behaviour by examining index returns from the stock markets in China and Taiwan. The sample period is from 1 January 1999 to 31 December 2014, and the data were obtained from Thomson Reuters Datastream. Although the sample period finishes in 2014, the data are more than sufficient to test the three hypotheses relating to the stock markets in China and Taiwan, both of which have Confucian cultures. The empirical results demonstrate significant herding behaviour under both general and specified markets conditions, including bull and bear markets, and high-low trading volume states. This paper contributes to the herding literature by examining three different hypotheses regarding the stock markets in China and Taiwan, and showing that there is empirical support for these hypotheses.
\end{abstract}

Keywords: herding behaviour; Confucian background; emerging market; frontier market; China market; Taiwan market

JEL Classification: B26; C58; D53; P34

\section{Introduction}

Herding is typically associated with a correlated behavioural pattern across individuals, and hence represents human behaviour that mimics the actions of other individuals. Numerous studies have emphasised that herding behaviour can be rational as well as irrational. Moreover, there are alternative types of such behaviour, such as information-based, reputation-based, compensation-based, and spurious herding forms [1,2].

Sequential decision theory states that each trader observes decisions made by others in making their own decisions. This is rational as the decisions of others can include useful information [3-10].

This paper is concerned with the stock markets of China and Taiwan. Stock markets in China provide an interesting insight for the analysis of herding behaviour. Since the establishment of the Shanghai Stock Exchange and the Shenzhen Stock Exchange in December 1990, two classes of shares 
have been issued, namely: (i) A-shares, which can be purchased and traded only by Chinese domestic investors, and are denominated in the local currency, the Renminbi; and (ii) B-shares, which were sold only to foreign investors before February 2001, after which they have been sold to both foreign and domestic investors. A-shares and B-shares are traded simultaneously on the Shanghai and Shenzhen exchanges.

The characteristics of investors of A-shares and B-shares are very different. A-shares are used by domestic individuals, who typically lack significant knowledge and experience in financial investments. The market for B-shares is dominated by foreign institutional investors, who tend to be more knowledgeable and sophisticated than A-share investors. The different characteristics of A-share and B-share investors may result in differences in the level of herding in each market, especially as the A-share market is relatively immature compared to its B-share counterparts $[1,11,12]$.

Having been established in 1961, which is much earlier than the creation of the stock markets in China, the Taiwan stock market is dominated by domestic individual investors, rather than institutional and foreign investors. Most individual investors tend to have less professional knowledge and cannot access information accurately and easily. However, there has been an increasing interest in the Taiwan stock market by foreign investors in recent years, following the lifting of trading restrictions on qualified foreign institutional investors in 2000 [13,14].

In a market that is dominated by domestic individual investors with limited access to information, it might be argued that the resulting information asymmetry would lead such individual investors to follow the actions of other investors, with the latter including more well-informed domestic and foreign institutional investors. Despite being what might be described as an emerging market, the Taiwan stock market is nevertheless highly developed (for further details, see Ref. [15]).

Moreover, a common characteristic of the stock markets in China and Taiwan is that they arise from Chinese culture, where Confucian management philosophy has been dominant. In this context, Ref. $[16,17]$ argue that Confucian markets tend to exhibit herding behaviour.

This study has two main contributions to herding literature. First, in addition to Confucian culture, these markets have specific common and contradictory characteristics; specifically, both are Chinese societies, though one has a free market economy under democratic governance, while the other has a market economy supervised under a communist regime. Furthermore, Taiwan is one of the four Tiger economies, whereas China has become the second largest economy in the world. Therefore, we feel that it is worth discussing and comparing these two markets. Second, the paper uses daily trading data covering a period of 16 years.

Although stock markets can and do differ across those that have a Confucian culture and those that do not, the primary purpose of this paper is to compare the stock markets in China and Taiwan, both of which have Confucian cultures. The issue of a control group would be important if the paper were to compare stock markets in countries that have a Confucian culture and those that do not.

For these reasons, this paper examines whether herding exists for China and Taiwan under both general and specific markets conditions, including bull and bear markets, and high-low trading volumes states.

The remainder of the paper is presented as follows. A literature review is given in Section 2. Methodological issues and the data to be used in the empirical analysis are discussed in Section 3, including the cross-sectional standard deviation model, the cross-sectional absolute deviation model, herding in up and down markets, and herding in high and low trading volumes. Three hypotheses are presented in Section 4, namely, whether herding exists in China and Taiwan, the existence of asymmetric herding in bull and bear markets, and also in high and low trading volumes. The empirical analysis is conducted in Section 5, where the outcomes of testing the three hypotheses are analysed. Some concluding remarks are given in Section 6. 


\section{Literature Review}

Parts of the review follow the presentation in Ref. $[5,18]$ examine herding in several international markets, specifically the USA, Hong Kong, Japan, South Korea, and Taiwan, by using daily stock price data from January 1963 to December 1997. The authors use the cross-sectional absolute deviation method, as an extension of Ref. [19]. They find no evidence of herding from the US and Hong Kong markets, and only a small amount from Japan. However, they find significant herding from the markets in South Korea and Taiwan.

The authors also find that macroeconomic information affects the formation of herding behaviour more significantly than firm-specific information. Furthermore, they suggest that stock return dispersion, as a function of market returns, is greater in up markets than in down markets. They also test the model suggested by Ref. [19] and find herding only for the Taiwan market.

Using the model of Ref. [5,12] find evidence of herding behaviour in Chinese A-shares. Owing to issues relating to the acquisition of accurate estimates of beta, as suggested in Ref. [5], the authors use the standard deviation in estimating the return dispersion, as in Ref. [12,19] also test the asymmetric impact of herding behaviour by varying returns, trading volumes, and volatility. They find herding behaviour in A-shares in the Shanghai market under rising market circumstances, with high volumes of trading of stocks and volatility. However, they find no evidence of herding in B-shares.

The main participants of A-share markets, which are considered as frontier markets, are local investors, who tend to lack sufficient talent and experience in finance. Investors in B-share markets, which are considered as emerging markets, are primarily foreigners with greater skills and knowledge of finance than investors in A-shares. For these reasons, Tan et al. [12] argue that the differences between A-shares and B-shares may affect the variance in herding. The authors also test herding and the cross-market information effect, but find no evidence of herding. Accordingly, the dissimilarity can be explained due to differences in the samples.

Lin and Swanson [20] also examine herding behaviour in the Taiwan stock market for 1996-2003, using one of the methods discussed in this paper. However, the authors focus only on foreign investors and the most liquid stocks, without classifying them into sectoral groups. They find no evidence to support the proposition that foreign investors display herding behaviour in this market. Lin et al. [21] examine daily trading data by foreign and domestic institutional investors for the fifty stocks that are most actively traded by institutional investors in Taiwan. The authors find the herding tendencies of stocks to be more prominent for small capitalized stocks with high share turnovers and high return volatility, thereby suggesting that market conditions and firm characteristics are significant factors driving herding behaviour.

Using buying and selling volume data, Chen, Wang, and Lin [13] find that qualified foreign institutional investors demonstrate herding behaviour in the Taiwan stock market. The authors show that industry effects, in addition to firm characteristics such as high previous returns and large market capitalization, explain the herding behaviour of foreign institutional investors.

Demirer, Kutan, and Chen [22] measure herding behaviour with daily data regarding stock returns for 689 stocks on the Taiwan Stock Exchange from January 1995 to December 2006. The authors use the models of Ref. [4,19] in addition to state space models. They find no evidence of herding in the model of Ref. [19], but find significant evidence in the non-linear model of Ref. [4] and the state space-based models in Ref. [23]. The authors also find that herding behaviour is stronger during periods of market losses than market gains.

Consequently, this paper suggests that investors need more diversified opportunities in periods of market losses. The authors emphasise the following in their analysis: (i) interesting and novel empirical results for an emerging yet relatively sophisticated Taiwan stock market at the sectoral level with firm-level data; (ii) an application of different models; and (iii) an analysis of the practical implications of different herding measures for investors who face both systematic and unexpected risks.

Yao, Ma, and He [24] measure the existence of herding behaviour in the China A-share and B-share markets. They use daily and weekly firm-level and market-level data of equity prices for all 
firms and indexes that are listed on the Shanghai Stock Exchange and the Shenzhen Stock Exchange from January 1999 to December 2008. Monthly data are also collected for all firms included in the data set. For the empirical analysis in testing herding behaviour, the authors use a modified version of the models of Ref. [4,19].

The empirical results show that herding behaviour is heterogeneous, so that herding is stronger in Chinese B-shares. In addition, the authors find that cross-market herding behaviour is stronger at the industry level, for the largest and smallest stocks, and for growth stocks relative to value stocks. The empirical results show that herding behaviour is greater when share prices are declining. Finally, the authors find that herding behaviour is affected by the regulatory reforms in China that are intended to increase investment efficiency.

In exploring the determinants of investment decision-making in international stock markets, Chang and Lin [16] analyse herding in daily market returns data and industrial index data for 50 stock markets for the cross-sectional absolute deviation of returns. The analysis uses an extended version of the model in Ref. [4]. In order to investigate the influence of culture on herding behaviour, the authors examine the Hofstede national culture indexes for the empirical analysis. In order to test behavioural pitfalls on the herding tendency, the authors use daily data of price-to-book ratios as proxies for excessive optimism, and daily trading volumes data are used as proxies for overconfidence and disposition.

The data set ranges from January 1965 to July 2011. The authors argue that their research examines the effects of culture and behavioural pitfalls in investments, and show that herding is exhibited in Confucian, as well as in less sophisticated stock markets. Moreover, the authors find that some cultural indexes have a high degree of correlation with herding behaviour.

\section{Methodology and Data}

\subsection{Data}

Ref. [12,19] find that the average cross-sectional absolute deviation (CSAD) calculated with the use of daily data is smaller than with the use of weekly or monthly data. This difference reflects the fact that, with weekly or monthly data, individual returns have a greater opportunity to stray further from the mean. Consequently, herding is less likely to be detected with weekly or monthly data. For this reason, this paper uses daily stock returns data for all firms on the Shanghai Stock Exchange (SSE), the Shenzhen Stock Exchange (SZSE), and the Taiwan Stock Exchange.

There are 425 Shanghai A-share firms (SHA) and 50 Shanghai B-share firms (SHB) at the SSE, 415 Shenzhen A-share firms (SZA) and 45 Shenzhen B-share firms (SZB) at the SZSE, and 455 firms comprising the Taiwan Capitalization Weighted Stock Index (TAIEX). In addition, we use daily index price data in each corresponding market. The data period spans from 1 January 1999 to 1 January 2015. A-share markets are considered as frontier markets, while both B-share markets and TAIEX are classified as emerging markets. The data are obtained from the Thomson Reuters Datastream database. The simple return method is used to calculate market returns and stock returns.

\subsection{Methodology}

The return dispersion method is a widely-used approach in most herding studies because it is a reliable method to measure herding behaviour. In the following subsections, we discuss several return dispersion models that are used in this paper.

\subsubsection{Cross-Sectional Standard Deviation Model}

Ref. $[4,19]$ use individual stock returns and market returns to detect herding behaviour. Christie and Huang [19] propose the following cross-sectional standard deviation (CSSD) model to detect herding behaviour:

$$
C S S D_{t}=\alpha+\beta^{L} D_{t}^{L}+\beta^{U} D_{t}^{U}+\varepsilon_{t}
$$


where

$$
\operatorname{CSSD}_{t}=\sqrt{\frac{\sum_{i=1}^{N}\left(R_{i, t}-R_{m, t}\right)^{2}}{(N-1)}}
$$

at time $t$ is the cross-sectional standard deviation; $D_{t}^{L}$ is a dummy variable of unity when market returns at $t$ lie in the extreme lower tail returns, and zero otherwise; $D_{t}^{U}$ is a dummy variable of one when market returns at $t$ lie in the extreme upper tail returns, and zero otherwise; $\alpha$ is a constant, both $\beta^{L}$ and $\beta^{U}$ are coefficients of $D_{t}^{L}$ and $D_{t}^{U}$, respectively; $\varepsilon_{t}$ is a random error term; $N$ is the number of firms; and $R_{i, t}$ and $R_{m, t}$ are individual stock returns of stock $i$ and market returns, respectively.

The model argues that if herding occurs when market returns lie in the extreme lower tail returns, then the estimate of $\beta^{L}$ will be significantly negative. On the other hand, if herding occurs when market returns lie in the extreme upper tail returns, then the estimate of $\beta^{U}$ will be significantly negative.

\subsubsection{Cross-Sectional Absolute Deviation Model}

One of the challenges associated with the CSSD model is that it must define extreme returns. Arguing that the definition in the CSSD model is arbitrary, Christie and Huang [19] suggest using 1\% and $5 \%$ as the cut-off points of the upper and lower tails of returns. In practice, investors may have different opinions regarding extreme returns, and it is possible that the returns will change dynamically.

In addition, herding behaviour may occur for the return distribution, but become more pronounced with market stress. Consequently, Christie and Huang [19] suggest that herding might be captured only for extreme returns. Ref. [4,25] suggest that Christie and Huang's [19] approach is too stringent to discover any empirical evidence of herding.

\subsubsection{Herding Behaviour}

Ref. $[4,12,25]$ suggest using the following cross-sectional absolute deviation (CSAD) model:

$$
\operatorname{CSAD} D_{t}=\alpha+\gamma_{1}\left|R_{m, t}\right|+\gamma_{2}\left(R_{m, t}\right)^{2}+\varepsilon_{t}
$$

to facilitate the detection of herding for all returns where, at time $t$, the cross-sectional absolute deviation given by:

$$
C S A D_{t}=\frac{1}{N} \sum_{i=1}^{N}\left|R_{i, t}-R_{m, t}\right|
$$

is a measure of the average absolute return dispersion from $R_{m, t}$ to measure the return dispersion, and $\left|R_{m, t}\right|$ and $R_{i, t}$ are the absolute value of market returns and individual stock returns of stock $i$, respectively.

If one analyses more than one financial market, it is possible to use the following model:

$$
\operatorname{CSAD} D_{i, t}=\alpha+\gamma_{1}\left|R_{i, m, t}\right|+\gamma_{2}\left(R_{i, m, t}\right)^{2}+\varepsilon_{i, t}
$$

where, for market $i$ at time $t, C S A D_{i, t}$ is the return dispersion calculated according to Equation (2), $\alpha$ is a constant, $\left|R_{i, m, t}\right|$ is the absolute value of market returns, $\left(R_{i, m, t}\right)^{2}$ is the squared value of market returns, and $\varepsilon_{i, t}$ is a random error term.

\subsubsection{Herding Behaviour in Up and Down Markets}

As the direction of market returns may affect investor behaviour, it is sensible to examine whether there is any asymmetry in herding behaviour, conditional on the market rising or falling. The herding 
regression model is estimated separately for positive and negative market returns. Specifically, the two-equation system can be written as:

$$
\begin{gathered}
C S A D_{i, t}^{U P}=\alpha+\gamma_{1}^{U P}\left|R_{i, m, t}^{U P}\right|+\gamma_{2}^{U P}\left(R_{i, m, t}^{U P}\right)^{2}+\varepsilon_{i, t} \text { If } R_{i, m, t}>0 \\
C S A D_{i, t}^{D O W N}=\alpha+\gamma_{1}^{D O W N}\left|R_{i, m, t}^{D O W N}\right|+\gamma_{2}^{D O W N}\left(R_{i, m, t}^{D O W N}\right)^{2}+\varepsilon_{i, t} \text { If } R_{i, m, t}<0
\end{gathered}
$$

where, for market $i$ at $t, C S A D_{i, t}^{U P}$ is the return dispersion when markets rise, $\alpha$ is a constant, $\left|R_{i, m, t}^{U P}\right|$ is the absolute value of market returns when the market rises, $\left(R_{i, m, t}^{U P}\right)^{2}$ is the squared value of market returns when the market rises, and $\varepsilon_{i, t}$ is a random error term. Variables with the superscript DOWN in Equation (5) refer to market falls. The variable $C S A D_{i, t}$ for each market in Equations (4) and (5) is defined in Equation (2). A negative and significant estimated coefficient $\gamma_{2}^{U P}$ or $\gamma_{2}^{D O W N}$ would indicate the presence of herding.

\subsubsection{Herding Behaviour in High and Low Trading Volumes}

The level of herding behaviour may be associated with the trading volume. For this reason, it is possible to examine any asymmetric effects during periods of high and low trading volume. The trading volume is given the superscript HIGH if the trading volume on day $t$ is greater than the moving average for the previous 30 days. The trading volume is given the superscript $L O W$ if it is less than the moving average for the previous 30 days. We also checked moving averages for periods of 7 and 90 days.

The empirical results of this paper are different from those in Tan et al. (2008), who use longer time periods of 60,90 , and 120 days. We used shorter time periods because many studies (for example, Chang et al. [4] suggest that the sentiment of investors typically occurs in a relatively short period of time. Therefore, we tested the following empirical models:

$$
\begin{gathered}
C S A D_{i, t}^{T V-H I G H}=\alpha+\gamma_{1}^{T V-H I G H}\left|R_{i, m, t}^{T V-H I G H}\right|+\gamma_{2}^{T V-H I G H}\left(R_{i, m, t}^{T V-H I G H}\right)^{2}+\varepsilon_{i, t} \\
C S A D_{i, t}^{T V-L O W}=\alpha+\gamma_{1}^{T V-L O W}\left|R_{i, m, t}^{T V-L O W}\right|+\gamma_{2}^{T V-L O W}\left(R_{i, m, t}^{T V-L O W}\right)^{2}+\varepsilon_{i, t}
\end{gathered}
$$

where, in market $i$ at $t, C S A D_{i, t}^{T V-H I G H}$ is the return dispersion when the trading volume is high, $\alpha$ is an intercept term, $\left|R_{i, m, t}^{T V-H I G H}\right|$ is the absolute value of market returns when the trading volume is high, $\left(R_{i, m, t}^{T V-H I G H}\right)^{2}$ is the squared value of market returns when the trading volume is high, and $\varepsilon_{i, t}$ is a random error term.

Similarly, variables with the superscript $T V-L O W$ refer to low trading volumes, where the superscript $T V$ refers to trading volume. The variable $C S A D_{i, t}$ in Equations (6) and (7) is calculated using Equation (2). A negative and statistically significant estimated coefficient $\gamma_{2}^{T V-H I G H}$ or $\gamma_{2}^{T V-L O W}$ would indicate herding.

\section{Three Hypotheses of Herding Behaviour}

There are three hypotheses regarding herding behaviour that will be tested in this paper. They are discussed separately in the following subsections.

\subsection{First Hypothesis}

Theoreticians and practitioners alike believe that there is herding behaviour in stock markets. It is hypothesised that this phenomenon also holds for the China and Taiwan stock markets. Therefore, we present the following hypothesis to test whether any herding exists in stocks in China and Taiwan: 
Hypothesis 1. Herding behaviour exists in the stock markets in China and Taiwan.

We note that there are different factors that may induce herding behaviour, including a high degree of government involvement in equity markets and heavy interest rate intervention by the central bank.

In this paper, we use Equation (8) to test Hypothesis 1. A negative and statistically significant estimated coefficient $\gamma_{2}$ would indicate herding. We note that $\gamma_{1}$ in Equation (3) [and also in Equation (2) cannot be used to test Hypothesis 1 . However, $\gamma_{1}$ is positive, implying that there is a linear relationship between the cross-sectional absolute deviation of returns, $C S A D_{t}$, and $\left|R_{i, m, t}\right|$. In addition, from Equation (3), we have a quadratic function for $C S A D_{t}$ and $\left|R_{i, m, t}\right|$ :

$$
\operatorname{CSAD}_{i, t}=\alpha+\gamma_{1}\left|R_{i, m, t}\right|+\gamma_{2}\left(R_{i, m, t}\right)^{2}
$$

where $C S A D_{t}$ reaches its maximum value when:

$$
\left|R_{i, m, t}\right|^{*}=-\left(\frac{\gamma_{1}}{2 \gamma_{2}}\right)
$$

If $\left|R_{i, m, t}\right|$ increases when the realised average daily returns in absolute terms are less than $\left|R_{i, m, t}\right|^{*}$, $C S A D_{t}$ is still associated with an increasing trend. However, as $\left|R_{i, m, t}\right|$ exceeds $\left|R_{i, m, t}\right|^{*}$, then CSAD starts to increase at a decreasing rate, which is captured by a negative and significant estimated coefficient $\gamma_{2}$. Therefore, the non-linear relationship between the market returns and the return dispersion would indicate herding behaviour. For this reason, a non-linear market return $\left(R_{i, m, t}\right)^{2}$ is included in the equation.

However, if market participants tend to follow aggregate market behaviour and ignore their own priors during periods of large average price movements, then the linear and increasing relation between dispersion and market returns will no longer hold. Instead, the proposed relationship could increase non-linearly, or even decrease non-linearly. The empirical model builds on this intuition.

\subsection{Second Hypothesis}

It is well-known that stock markets perform differently in bull runs and bear markets [26,27]. Some studies, for example, Ref. [28], have found that herding behaviour can be different in bull runs and bear markets. It is common (see Ref. $[29,30]$ ) for the negative fear of potential loss when the market crashes to exceed the positive effects of potential gains under market booms. McQueen, Pinegar, and Thorley [31] claim that this is because while all stocks tend to respond quickly to negative macroeconomic news, small stocks tend to be slow in reacting to positive news.

As positive news often entails an increase in stock prices, a slow reaction implies a delay in reacting to good news. Therefore, herding is more pronounced during market downturns than upturns $[24,28,32]$.

It is hypothesised that these phenomena also hold for the stock markets in China and Taiwan. Consequently, we propose the following hypothesis to test whether investors tend to display herding behaviour more in downturns than upturns:

Hypothesis 2. Asymmetric herding behaviour exists in the stock markets in both China and Taiwan during bull and bear markets.

Hypothesis 2 states that herding exists in bull and bear markets in the stock markets in China and Taiwan if the estimated coefficients $\gamma_{2}^{U P}$ and $\gamma_{2}^{D O W N}$ in Equations (4) and (5), respectively, are significantly different from zero. Chang et al. (2000) have shown that when $\gamma_{1}^{U P}$ and $\gamma_{1}^{D O W N}$ reach a certain value, both $C S A D_{i, t}^{U P}$ and $C S A D_{i, t}^{D O W N}$ start to decrease, or at least increase less proportionately with the market returns because there is a non-linear relationship between return dispersion and 
market returns. Therefore, $\gamma_{1}^{U P}$ and $\gamma_{1}^{D O W N}$ cannot be used to test Hypothesis 2, according to which herding exists in both bull and bear markets.

\subsection{Third Hypothesis}

It is also well-known (see Ref. [33]) that stock returns depend on the magnitude of the trading volume. In addition, the relationship between stock returns and trading volume is different for different levels of herding behaviour under alternative market conditions [24,34].

It is hypothesised that these phenomena also hold for the stock markets in China and Taiwan. Therefore, we propose the following hypothesis to test whether the level of herding behaviour is associated with trading volume:

Hypothesis 3. Asymmetric herding behaviour exists in the stock markets in both China and Taiwan in high and low trading volumes.

We confirm Hypothesis 3 that herding exists in the high and low volatility states of the stock markets in China and Taiwan if the estimated coefficients $\gamma_{2}^{T V-H I G H}$ and $\gamma_{2}^{T V-L O W}$ in Equations (6) and (7), respectively, are significantly different from zero. Chang et al. (2000) have shown that when $\gamma_{1}^{T V-H I G H}$ or $\gamma_{1}^{T V-L O W}$ reaches a certain value, $C S A D_{i, t}^{T V-H I G H}$ or $C S A D_{i, t}^{T V-L O W}$ will start to decrease, or at least increase less proportionately with the market returns because there is a non-linear relationship between return dispersion and market returns. Therefore, $\gamma_{1}^{T V-H I G H}$ or $\gamma_{1}^{T V-L O W}$ cannot be used to test Hypothesis 3, according to which herding exists in high and low volatility states in the stock markets in China and Taiwan.

\section{Empirical Analysis}

\subsection{Descriptive Statistics}

This paper applies the CSAD return dispersion model, as given in Equations (2)-(7), and tests Hypotheses 1-3 to investigate whether there is any herding behaviour by examining the index returns from the stock markets in China and Taiwan. In order to do so, we first estimated the univariate descriptive statistics for the return dispersion and market returns of the markets in China and Taiwan. By definition, CSAD takes on a minimum value of zero when all individual stock returns move in perfect unison with the market, and increases when the returns of individual stocks deviate from the market returns.

Table 1 shows the descriptive statistics of market returns and CSAD return dispersions for the stock markets in both China and Taiwan. The average daily returns range from a low of $0.0129 \%$ for the TAIEX market to a high of $0.0899 \%$ for the SZB market. Daily returns of B-share markets consistently have higher mean values than those of A-shares markets, along with higher standard deviations. This evidence is consistent with the findings in Chang et al. (2000) and Tan et al. (2008) in that, in more well-developed markets, the greater the mean values of market returns and the higher the volatility.

The lowest daily returns (-9.780) were observed on 6 August 2001 in the SHB market, while the second lowest minimum daily returns (-9.493) were observed on 6 July 1999 in the SZB market. Maximum daily returns also occurred around the same time. The lowest and highest daily returns were observed in the B-share markets as the B-shares were made accessible to foreign investors from February 2001.

The descriptive statistics show that the mean values of CSAD for A-shares are consistently higher than those of B-shares, and are also accompanied by higher standard deviations. Chiang and Zheng [35] argue that higher standard deviations in similar markets suggest that the markets had unusual cross-sectional variations due to unexpected news or shocks. The TAIEX market also has a relatively high mean returns dispersion, which is accompanied by the lowest standard deviation. 
This observation is consistent with the herding behaviour according to which investors in the TAIEX market are more likely to react efficiently to news and diverse shocks. One explanation is that sophisticated investors in emerging markets have more information and analytical tools that allow them to assess and reallocate their investments, thereby leading to a higher dispersion of stock returns and lower standard deviations.

Table 1. Descriptive statistics of cross-sectional absolute deviation (CSAD) and market returns of the stock markets in China and Taiwan.

\begin{tabular}{|c|c|c|c|c|c|c|c|c|c|c|}
\hline & \multicolumn{2}{|c|}{ SHA } & \multicolumn{2}{|c|}{ SHB } & \multicolumn{2}{|c|}{ SZA } & \multicolumn{2}{|c|}{ SZB } & \multicolumn{2}{|c|}{ TAIEX } \\
\hline & CSAD & $\mathbf{R}_{\mathrm{m}}$ & CSAD & $\mathbf{R}_{\mathrm{m}}$ & CSAD & $\mathbf{R}_{\mathrm{m}}$ & CSAD & $\mathbf{R}_{\mathrm{m}}$ & CSAD & $\mathbf{R}_{\mathrm{m}}$ \\
\hline Mean & $1.504^{* * *}$ & 0.028 & $1.107^{* * *}$ & $0.076^{* *}$ & $1.453^{* * *}$ & 0.038 & $1.272^{* * *}$ & $0.089^{* * *}$ & $1.549^{* * *}$ & 0.012 \\
\hline Std. dev. & 0.767 & 1.511 & 0.686 & 2.055 & 0.684 & 1.656 & 0.693 & 1.957 & 0.656 & 1.398 \\
\hline Minimum & 0 & -8.845 & 0 & -9.780 & 0 & -8.539 & 0 & -9.493 & 0 & -9.460 \\
\hline Maximum & 7.220 & 9.856 & 5.129 & 9.914 & 6.678 & 9.680 & 5.287 & 9.857 & 6.014 & 6.740 \\
\hline Skewness & $0.835^{* * *}$ & $0.066^{*}$ & $1.132 * * *$ & $0.280^{* * *}$ & $0.589^{* * *}$ & $-0.293^{* * *}$ & $0.773^{* * *}$ & $0.385^{* * *}$ & $0.315^{* * *}$ & $-0.149^{* * *}$ \\
\hline Kurtosis & $6.225^{* * *}$ & $8.048^{* * *}$ & $5.741^{* * *}$ & $8.446^{* * *}$ & $6.833^{* * *}$ & $6.554^{* * *}$ & $5.044^{* * *}$ & $8.391 * * *$ & $5.024^{* * *}$ & $6.308^{* * *}$ \\
\hline $\mathrm{N}$ obs. & \multicolumn{2}{|c|}{3982} & \multicolumn{2}{|c|}{4174} & \multicolumn{2}{|c|}{3877} & \multicolumn{2}{|c|}{4174} & \multicolumn{2}{|c|}{3779} \\
\hline $\mathrm{N}$ firms & \multicolumn{2}{|c|}{425} & \multicolumn{2}{|c|}{50} & \multicolumn{2}{|c|}{415} & \multicolumn{2}{|c|}{45} & \multicolumn{2}{|c|}{455} \\
\hline
\end{tabular}

Note: CSAD is defined as cross-sectional absolute deviation. $\mathrm{R}_{\mathrm{m}}$ is the market return. SHA, SHB, SZA, SZB, and TAIEX are stated in Section 4.1. ${ }^{* * * *}{ }^{* *}$, and ${ }^{*}$ represent statistical significance at the $1 \%, 5 \%$, and $10 \%$ levels, respectively.

In addition to the above results, Ref. [25,31] argue that investors may fear potential losses in downturns more than they enjoy potential gains in upturns. This proposition leads investors to display herding behaviour. The consequence is a reduction in the returns dispersion. The empirical findings in this paper are consistent with such an argument.

The stationarity of the measures of the returns dispersion is evaluated through the implementation of the Augmented Dickey-Fuller (ADF) test. As all the series are found to be stationary, we do not report details of the ADF test results. After reviewing the relevant literature, we have developed the three hypotheses presented in Section 4 to test whether the stock markets in China and Taiwan exhibit herding under different conditions. We discuss each of the hypotheses in the following subsections.

\subsection{Testing Herding Behaviour (H1)}

In order to test the first proposed hypothesis as to whether there is any herding behaviour in the stock markets in both China and Taiwan, we examined whether the estimated coefficients in Equation (3) are significantly less than zero, as discussed in Section 4.1. The empirical findings are reported in Table 2. According to the definition of the empirical model in Equation (3), a negative and statistically significant estimated coefficient $\gamma_{2}$ would indicate the presence of herding.

Table 2. Results of herding behaviour in the sample stock markets.

\begin{tabular}{ccccc}
\hline Market Name (N) & $\alpha$ & $\gamma \mathbf{1}$ & $\gamma^{\mathbf{2}}$ & Adj. $^{\mathbf{2}}$ \\
\hline SHA (3982) & $1.053(59.32)^{* * *}$ & $0.564(27.33)^{* * *}$ & $-0.053(-15.09)^{* * *}$ & 0.249 \\
SHB (4174) & $0.668(48.15)^{* * *}$ & $0.479(32.19)^{* * *}$ & $-0.043(-22.42)^{* * *}$ & 0.290 \\
SZA (3877) & $1.000(56.62)^{* * *}$ & $0.473(23.26)^{* * *}$ & $-0.035(-8.55)^{* * *}$ & 0.299 \\
SZB (4174) & $0.839(55.36)^{* * *}$ & $0.479(31.15)^{* * *}$ & $-0.044(-21.24)^{* * *}$ & 0.273 \\
TAIEX (3779) & $1.126(47.78)^{* * *}$ & $0.588(12.81)^{* * *}$ & $-0.072(-5.47)^{* * *}$ & 0.267 \\
\hline
\end{tabular}

Notes: Numbers in parentheses are $t$-statistics from Ref. [36] consistent standard errors. ${ }^{* * *},{ }^{* *}$, and ${ }^{*}$ represent statistical significance at the $1 \%, 5 \%$, and $10 \%$ levels, respectively. This table reports the results of the estimation of the empirical model in Equation (3): $C S A D_{i, t}=\alpha+\gamma_{1}\left|R_{i, m, t}\right|+\gamma_{2}\left(R_{i, m, t}\right)^{2}+\varepsilon_{i, t}$.

Table 2 shows that the estimates of $\gamma_{2}$ are significantly negative in all markets at the $1 \%$ level, thereby supporting the first hypothesis and suggesting that there is strong herding behaviour in the Taiwan stock index, TAIEX, and all the Chinese stock indexes, including SHA, SHB, SZA, and SZB. The empirical findings do not reject Hypothesis 1, thereby suggesting that there is significant herding 
behaviour in the SHB, SZB, and TAIEX stock markets, which are emerging markets. These results are consistent with the empirical findings in Ref. $[4,12,16]$.

The coefficients on the linear component of $\left|R_{i, m, t}\right|$ are positive and significant, thereby indicating that there is both a significant and positive linear relationship between $C S A D_{i, t}$ and $\left|R_{i, m, t}\right|$. Table 2 shows that the combined effects of the herding effect and the linear relationship between $C S A D_{i, t}$ and $\left|R_{i, m, t}\right|$ explain from $24.9 \%$ (SHA) to $29.9 \%$ (SZA) of the total variation in $C S A D_{i, t}$. In addition, substituting the estimated coefficients for the SHA market $\left(\gamma_{1}=0.564\right.$ and $\left.\gamma_{2}=-0.053\right)$ into the quadratic relationship in Equation (8) indicates that $C S A D_{t}$ reaches a maximum when the following holds:

$$
\left|R_{i, m, t}\right|=\left|R_{i, m, t}\right|^{*}=5.321 \%
$$

This outcome suggests that, during large price movements in market returns that exceed the threshold level $\left|R_{i, m, t}\right|^{*}$, the $C S A D_{t}$ increases at a decreasing rate, as in Figure 1.

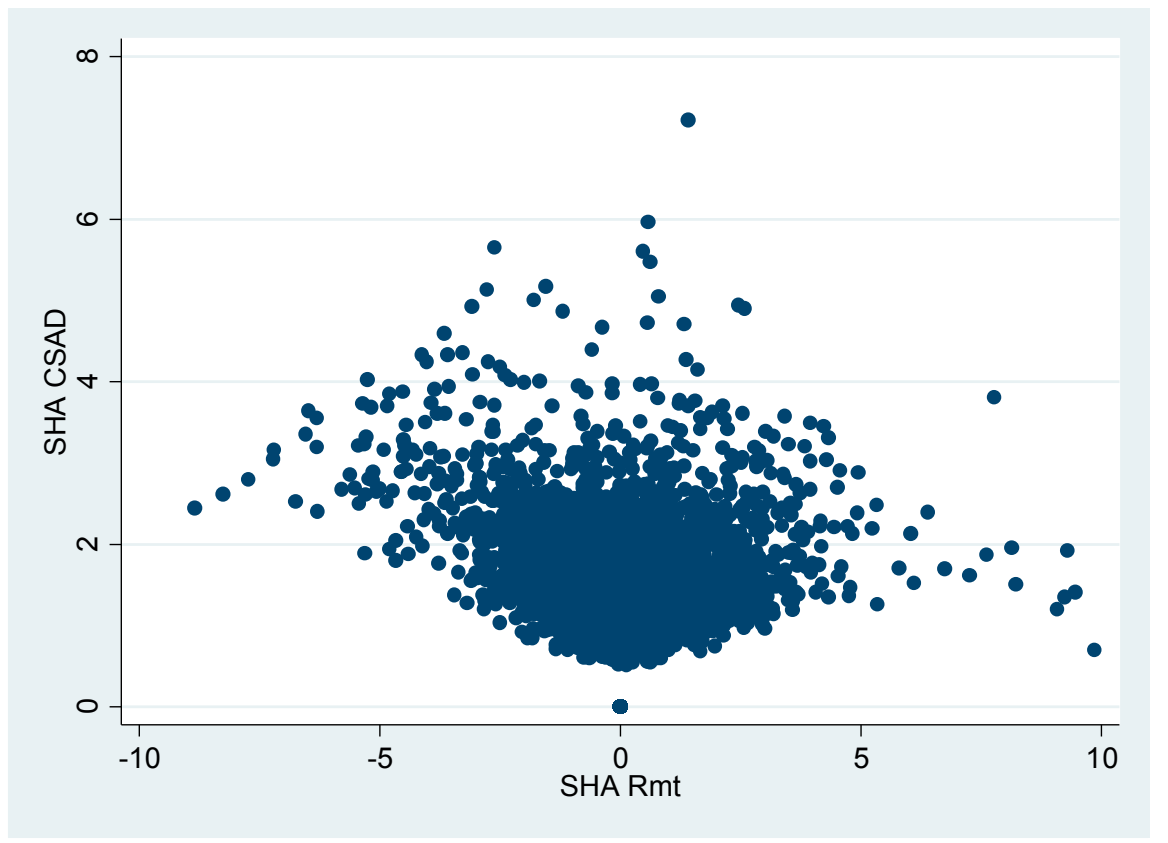

Figure 1. Relationship between the daily return dispersion $\left(C S A D_{i, t}\right)$ and equally-weighted market return $\left(R_{i, m, t}\right)$ for the SHA market.

In addition to the negative and statistically significant estimated coefficient, $\gamma_{2}$, the sizes of the coefficient capture the magnitudes of the herding behaviour in each market [34]. As the largest value of the estimated coefficient, $\gamma_{2}$, is found in the TAIEX market (as measured at -0.072), while the smallest value lies in the SZA market (as measured at -0.035 ), the estimated coefficients show that herding behaviour is greater in the TAIEX market than in the emerging markets in China.

\subsection{Testing Herding Behaviour in Up and Down Markets (H2)}

The second hypothesis tests whether herding is asymmetric in the stock markets in China and Taiwan when they rise and fall. Table 3 reports the outcomes in testing the second hypothesis. According to the models in Equations (4) and (5), the negative and statistically significant estimated coefficients, $\gamma_{2}^{U P}$ and $\gamma_{2}^{D O W N}$, respectively, indicate that there is herding behaviour due to the up and down markets. If the magnitudes of $\gamma_{2}^{U P}$ and $\gamma_{2}^{D O W N}$ are different, then the additional herding behaviours due to the up and down markets are different, thereby showing that herding behaviour is asymmetric in both up and down markets. 
Table 3. Results of herding behaviour in the stock markets in China and Taiwan in up and down markets.

\begin{tabular}{|c|c|c|c|c|c|c|c|c|c|}
\hline \multirow{2}{*}{$\begin{array}{l}\text { Market Name } \\
\text { (N) }\end{array}$} & \multicolumn{4}{|c|}{ UP Market $R_{i, m, t}>0$} & \multirow{2}{*}{$\begin{array}{l}\text { Market Name } \\
\text { (N) }\end{array}$} & \multicolumn{4}{|c|}{ DOWN Market $R_{i, m, t}<0$} \\
\hline & $\alpha$ & $\gamma \mathbf{1}^{\mathrm{UP}}$ & $\gamma 2^{\mathrm{UP}}$ & Adj. $R^{2}$ & & A & $\gamma 1^{\text {DOWN }}$ & $\gamma 2^{\text {DOWN }}$ & Adj. $R^{2}$ \\
\hline SHA (2224) & $0.916(39.79) * * *$ & $0.605(22.96)^{* * *}$ & $-0.066(-13.97)^{* * *}$ & 0.236 & SHA (1758) & $1.309(53.61)^{* * *}$ & $0.391(11.65)^{* * *}$ & $-0.015(-2.39)^{* *}$ & 0.272 \\
\hline SHB (2314) & $0.560(31.99)^{* * *}$ & $0.546(28.29)^{* * *}$ & $-0.051(-21.42) * * *$ & 0.337 & SHB (1860) & $0.840(40.19)^{* * *}$ & $0.356(15.46)^{* * *}$ & $-0.027(-8.32) * * *$ & 0.227 \\
\hline SZA (2237) & $0.862(38.75)^{* * *}$ & $0.551(22.31)^{* * *}$ & $-0.059(-11.78) * * *$ & 0.284 & SZA (1640) & $1.288(58.35)^{* * *}$ & $0.291(11.73)^{* * *}$ & $-0.000(-0.01)$ & 0.338 \\
\hline SZB (2372) & $0.700(36.27)^{* * *}$ & $0.581(30.21) * * *$ & $-0.056(-24.63) * * *$ & 0.329 & SZB (1802) & $1.082(50.06)^{* * *}$ & $0.282(11.34)^{* * *}$ & $-0.017(-4.39) * * *$ & 0.197 \\
\hline TAIEX (2058) & $0.960(39.23) * * *$ & $0.783(23.80) * * *$ & $-0.111(-12.78)^{* * *}$ & 0.329 & TAIEX (1721) & $1.332(50.91)^{* * *}$ & $0.381(8.02)^{* * *}$ & $-0.034(-2.62)^{* * *}$ & 0.199 \\
\hline
\end{tabular}

Notes: Numbers in parentheses are $t$-statistics based on Ref. [36] consistent standard errors. ${ }^{* * *}, * *$ and $*$ represent statistical significance at the $1 \%, 5 \%$, and $10 \%$ levels, respectively. This table reports the results of the estimation of the empirical model in Equations (4) and (5): $C S A D_{i, t}^{U P}=\alpha+\gamma_{1}^{U P}\left|R_{i, m, t}^{U P}\right|+\gamma_{2}^{U P}\left(R_{i, m, t}^{U P}\right)^{2}+\varepsilon_{i, t}$ if $R_{i, m, t}>0 C S A D_{i, t}^{D O W N}=\alpha+\gamma_{1}^{D O W N}\left|R_{i, m, t}^{D O W N}\right|+$ $\gamma_{2}^{D O W N}\left(R_{i, m, t}^{D O W N}\right)^{2}+\varepsilon_{i, t}$ if $R_{i, m, t}<0$. 
Table 3 shows that the estimated coefficient, $\gamma_{2}^{U P}$, is negative and statistically significant in all markets at the $1 \%$ level, thereby implying that there is herding behaviour due to the up markets in all cases that have been considered. However, the coefficient, $\gamma_{2}^{D O W N}$, is negative and statistically significant at the $1 \%$ level only for SHB, SZB, and TAIEX, significant at the $5 \%$ level for SHA, and not significant for SZA. These results suggest that there is herding behaviour due to the down markets for SHB, SZB, TAIEX, and SHA, but not for SZA. It follows that Hypothesis 2 is rejected only for the SZA market.

For SZA, as the estimated coefficient $\gamma_{2}^{U P}$ is significant, while the estimated coefficient $\gamma_{2}^{D O W N}$ is not significant, it follows that herding behaviour is asymmetric in the up and down markets, respectively. In addition, for SHB, SZB, TAIEX, and SHA, as both the estimated coefficients, $\gamma_{2}^{U P}$ and $\gamma_{2}^{D O W N}$, are significant, but of different magnitudes, the herding behaviour is asymmetric in the up and down markets. Therefore, Hypothesis 2 is supported empirically for the SHB, SZB, TAIEX, and SHA markets.

The outcomes of the tests of Hypothesis 2 are consistent with the empirical results as reported in Ref. [12,35]. A possible explanation for these findings is that institutional investors in the China and Taiwan stock markets may engage in positive feedback trading by buying additional shares when prices are rising, and selling them when the prices are falling $[37,38]$. However, the empirical findings in this paper are different from those in Ref. [4,24,31,34], among others, who find that investors behave more homogeneously when stock markets are declining.

Breaking down the up and down markets, the up market states are bull markets that are characterized by optimism under a strong economy, with confident investors who expect stock prices to continue rising $[39,40]$. On the other hand, down markets are bear markets that are characterized by falling prices and shrouded in pessimism. Bear markets typically occur before the economy starts to contract [15,41].

\subsection{Testing Herding Behaviour during HIGH and LOW Trading Volume States (H3)}

The third hypothesis conjectures that asymmetric herding exists in the China and Taiwan stock markets during high and low trading volume states. Table 4 reports the empirical results in testing the third hypothesis. According to the definitions in Equations (6) and (7), negative and statistically significant estimated coefficients, $\gamma_{2}^{T V-H I G H}$ and $\gamma_{2}^{T V-L O W}$, indicate herding behaviour in the high and low trading volume states, respectively.

The results in Table 4 show that the estimated coefficient, $\gamma_{2}^{T V-H I G H}$, is negative and statistically significant for all the markets, except for SZA.

On the other hand, the estimated coefficient, $\gamma_{2}^{T V-L O W}$, is negative and significant in all markets at the $1 \%$ level, thereby implying that there is a strong indication of herding in all markets during the low trading states. For SZA, as the estimated coefficient, $\gamma_{2}^{T V-H I G H}$, is negative, but not significant, while the estimated coefficient, $\gamma_{2}^{T V-L O W}$, is significantly negative, it follows that herding behaviour is asymmetric in the up and down markets, respectively.

In short, the empirical findings strongly suggest that there is evidence of herding in sample markets when the trading volume is either high or low. Nonetheless, herding is greater when the trading volume is low than when it is high. A possible explanation is that, during low trading volume states, less trading happens, and thus share returns become naturally more homogenous and correlated, which can lead to ineffective herding behaviour.

Ref. [12,24] find that herding is greater when the trading volume is high. It is worth noting that the empirical results in this paper find that herding behaviour is greater when the trading volume is high. However, it is also found that herding is even greater when the trading volume is low, which is also in line with the findings of Ref. [28].

This paper also examines Hypothesis 3 with moving averages of 7 and 90 days. The empirical results show that the 7-day and 90-day moving averages are consistent with the use of 30-day moving averages. In summary, the empirical results provide very strong evidence in favour of Hypothesis 3. 
Table 4. Results of herding behaviour in the China and Taiwan stock markets during HIGH and LOW trading volume states.

\begin{tabular}{|c|c|c|c|c|c|c|c|c|c|}
\hline \multirow{2}{*}{$\begin{array}{l}\text { Market Name } \\
\text { (N) }\end{array}$} & \multicolumn{4}{|c|}{$\mathrm{TV}^{\mathrm{HIGH}}>\mathrm{TV}_{\mathrm{t}-30}^{\mathrm{MA}}$} & \multirow{2}{*}{$\begin{array}{l}\text { Market Name } \\
\text { (N) }\end{array}$} & \multicolumn{4}{|c|}{$\mathrm{TV}^{\mathrm{LOW}}<\mathrm{TV}^{\mathrm{MA}}{ }_{\mathrm{t}-30}$} \\
\hline & $\alpha$ & $\gamma 1^{\text {TV-HIGH }}$ & $\gamma 2^{\mathrm{TV}-\mathrm{HIGH}}$ & Adj. $R^{2}$ & & $\alpha$ & $\gamma 1^{\text {TV-LOW }}$ & $\gamma 2^{\text {TV-LOW }}$ & Adj. $R^{2}$ \\
\hline SHA (2003) & $1.423(58.53)^{* * *}$ & $0.297(10.03)^{* * * *}$ & $-0.022(-3.83)^{* * *}$ & 0.111 & SHA (1949) & $0.790(34.87)^{* * *}$ & $0.800(25.31)^{* * * *}$ & $-0.082(-12.93)^{* * *}$ & 0.371 \\
\hline SHB (1783) & 0.962 & $0.3224(14.24)^{* * *}$ & $-0.027(-9.74)^{* * *}$ & & & $0.532(35.06)^{* * *}$ & 41) *** & $18.29)^{* * *}$ & 0.341 \\
\hline SZA (1975) & $1.357(56.70)^{* * * *}$ & $0.211(6.85)^{* * *}$ & $-0.005(-0.79)$ & 0.167 & SZA (1872) & $0.752(34.08)^{* * * *}$ & $0.670(23.93)^{* * *}$ & $-0.05(-8.40)^{* * *}$ & 0.421 \\
\hline SZB (1770) & $1.150(45.40)^{* * *}$ & $0.319(14.12)^{* * *}$ & $-0.027(-9.20)^{* * *}$ & 0.156 & SZB (2374) & $0.689(39.9)^{* * *}$ & $0.542(26.19)^{* * *}$ & $-0.054(-15.88)^{* * *}$ & 0.306 \\
\hline TAIEX (1835) & $1.382(55.5)^{* * *}$ & $0.416(10.38)^{* * *}$ & $-0.042(-3.78)^{* * *}$ & 0.198 & TAIEX (1914) & $0.953(28.32) * * *$ & $0.653(8.38)^{* * * *}$ & $-0.082(-14.05)^{* * *}$ & 0.307 \\
\hline
\end{tabular}

Notes: Numbers in parentheses are $t$-statistics based on Ref. [36] consistent standard errors. ${ }^{* * *},{ }^{* *}$ and * represent statistical significance at the $1 \%, 5 \%$, and $10 \%$ levels, respectively. Thirty-day moving averages of trading volume (TV) are given when TV is high and low. This table reports the results of the estimation of Equations (6) and (7): CSAD $D_{i, t}^{T V}-H I G H=$ $\alpha+\gamma_{1}^{T V-H I G H}\left|R_{i, m, t}^{T V-H I G H}\right|+\gamma_{2}^{T V-H I G H}\left(R_{i, m, t}^{T V-H I G H}\right)^{2}+\varepsilon_{i, t}, C S A D_{i, t}^{T V-L O W}=\alpha+\gamma_{1}^{T V-L O W}\left|R_{i, m, t}^{T V-L O W}\right|+\gamma_{2}^{T V-L O W}\left(R_{i, m, t}^{T V-L O W}\right)^{2}+\varepsilon_{i, t}$. 


\section{Concluding Remarks}

As it has been argued in the literature that markets with a Confucian background are more likely to exhibit herding behaviour, this paper examined the stock markets in China and Taiwan through empirical analysis. There was overwhelming evidence of herding behaviour from the full sample markets. The three hypotheses were tested against empirical evidence, and were all supported by the data.

In respect to the first hypothesis, there was significant herding from all markets, regardless of whether they were emerging or frontier markets.

In addition to testing the second and third hypotheses, it was found that herding is greater in up markets than in down markets, and was also greater during low trading volume states than during high trading volumes. The up markets are positive and profitable for investors, and are key features of bull markets. During a bull market, investors are more optimistic with regards to trading.

However, this does not mean that investors make decisions entirely on they own. When investors are overly optimistic, they exhibit risky behaviour by making risky investment decisions, such as buying too many stocks, based either on their own decisions or by following other traders [40]. Therefore, bull markets might be creating a foundation for possible herding behaviour.

Moreover, previous research has suggested that one of the indicators of down markets is a reduction in trading volume, which follows uncertainty among investors. Investors perceive falls in trading volume with an understandable fear that the market might also fall. Consequently, investors are more likely to convert shares into fast cash [39,42].

Therefore, this sentiment makes the fear among investors contagious, thereby leading to the formation of herding. On the other hand, in bear markets, markets cool down and less trading happens, and thus stock returns become less diverse and more correlated, which may lead to ineffective herding behaviour.

In general, this paper detected overwhelming herding from the entire sample markets. For this reason, all three hypotheses were supported strongly by the data. This paper analysed the stock markets of China and Taiwan empirically based on 15 years of daily observations, which offers another contribution to the literature on herding. Although the sample period finishes in 2014, the data are more than sufficient to test the three hypotheses relating to the stock markets in China and Taiwan, both of which have Confucian cultures.

Although the stock market in Taiwan is relatively developed compared to the markets in China, it still displayed strong herding behaviour. Therefore, further research is necessary to examine herding behaviour beyond the maturity of market settings. Moreover, the authors of this paper intend to include non-Confucian markets as a control group in future research to ascertain if herding behaviour is found in Confucian and non-Confucian countries.

Author Contributions: Conceptualization, B.J.M.-U., M.M. and W.-K.W.; Data curation, B.J.M.-U.; Formal analysis, B.J.M.-U., M.M. and W.-K.W.; Funding acquisition, M.M.; Investigation W.-K.W.; Methodology, M.M.; Project administration, M.M.; Resources, M.M.; Software, B.J.M.-U.; Supervision, M.M., M.M. and W.-K.W.; Writing—original draft, B.J.M.-U.; Writing—review \& editing, M.M.

Acknowledgments: The authors are most grateful for the helpful comment $\mathrm{s}$ and suggestions of three referees. The second author wishes to thank the Australian Research Council and the Ministry of Science and Technology (MOST), Taiwan, for financial support. The fourth author would like to acknowledge financial support from Asia University, China Medical University Hospital, the Hang Seng University of Hong Kong, the Research Grants Council of Hong Kong (Project Number 12500915), and the Ministry of Science and Technology (MOST, Project Numbers 106-2410-H-468-002 and 107-2410-H-468-002-MY3), Taiwan.

Conflicts of Interest: The authors declare no conflict of interest. 


\section{References}

1. Zheng, Y.; Chen, H.; Wong, W.-K. China's stock market integration with a leading power and a close neighbor. J. Risk Financ. Manag. 2009, 2, 38-74.

2. Spyrou, S. Herding in Financial Market: A Review of Literature. Rev. Behav. Financ. 2013, 5, 175-194. [CrossRef]

3. Bikhchandani, S.; Sharma, S. Herd behavior in financial markets. IMF Staff Papers 2000, 47, 279-310.

4. Chang, E.C.; Cheng, J.W.; Khorana, A. An examination of herd behaviour in equity markets: An international perspective. J. Bank. Financ. 2000, 24, 1651-1679. [CrossRef]

5. Chang, W.C.; Wong, W.-K.; Koh, B.K. Chinese values in Singapore: Traditional and modern. Asian J. Soc. Psychol. 2003, 6, 5-29. [CrossRef]

6. Wong, W.-K.; Penm, J.H.W.; Terrell, R.D.; Lim, K.Y.C. The relationship between stock markets of major developed countries and Asian emerging markets. Adv. Decis. Sci. 2004, 8, 201-218.

7. Fong, W.M.; Wong, W.-K.; Lean, H.H. International momentum strategies: A stochastic dominance approach. J. Financ. Mark. 2005, 8, 89-109. [CrossRef]

8. Bikhchandani, S.; Hirshleifer, D.; Welch, I. A theory of fads, fashion, custom, and cultural change as informational cascades. J. Polit. Econ. 1992, 100, 992-1026. [CrossRef]

9. Scharfstein, D.S.; Stein, J.C. Herd behavior and investment. Am. Econ. Rev. 1990, 80, 465-479.

10. Devenow, A.; Welch, I. Rational herding in financial economics. Eur. Econ. Rev. 1996, 40, 603-615. [CrossRef]

11. Demirer, R.; Kutan, A.M. Does herding behavior exist in Chinese stock markets? J. Int. Financ. Mark. Inst. Money 2006, 16, 123-142. [CrossRef]

12. Tan, L.; Chiang, T.C.; Mason, J.R.; Nelling, E. Herding behaviour in Chinese stock markets: An examination of A and B shares. Pacific Basin Financ. J. 2008, 16, 61-77. [CrossRef]

13. Chen, Y.F.; Wang, C.Y.; Lin, F.L. Do qualified foreign institutional investors herd in Taiwan's securities market? Emerg. Mark. Financ. Trade 2008, 44, 62-74. [CrossRef]

14. Chiang, T.C.; Li, J.; Tan, L. Empirical investigation of herding behavior in Chinese stock markets: Evidence from quantile regression analysis. Global Financ. J. 2010, 21, 111-124. [CrossRef]

15. Clark, E.; Qiao, Z.; Wong, W.K. Theories of risk: Testing investor behaviour on the Taiwan stock and stock index futures markets. Econ. Inq. 2016, 54, 907-924. [CrossRef]

16. Chang, C.H.; Lin, S.J. The effects of national culture and behavioural pitfalls on investors' decision-making: Herding behaviour in international stock markets. Int. Rev. Econ. Financ. 2015, 37, 380-392. [CrossRef]

17. Beckmann, D.; Menkhoff, L.; Suto, M. Does culture influence asset managers' views and behaviour? J. Econ. Behav. Organ. 2008, 67, 624-643. [CrossRef]

18. Munkh-Ulzii, B.; Moslehpour, M.; Van Kien, P. Empirical models of herding behaviour for Asian countries with Confucian Culture. In Predictive Econometrics and Big Data; Kreinovich, V., Sriboonchitta, S., Chakpitak, N., Eds.; Studies in Computational Intelligence; Springer Nature: Basingstoke, UK, 2018; Volume 753.

19. Christie, W.G.; Huang, R.D. Following the Pied Piper: Do individual returns herd around the market? Financ. Anal. J. 1995, 51, 31-37. [CrossRef]

20. Lin, A.Y.; Swanson, P.E. The behaviour and performance of foreign investors in emerging equity markets: Evidence from Taiwan. Int. Rev. Financ. 2003, 4, 189-210. [CrossRef]

21. Lin, A.Y.; Huang, L.S.; Chen, M.Y. Price co-movement and institutional performance following large market movements. Emerg. Mark. Financ. Trade 2007, 43, 37-61. [CrossRef]

22. Demirer, R.; Kutan, A.M.; Chen, C.D. Do investors herd in emerging stock markets? Evidence from the Taiwanese market. J. Econ. Behav. Organ. 2010, 76, 283-295. [CrossRef]

23. Hwang, S.; Salmon, M. Market stress and herding. J. Empir. Financ. 2004, 11, 585-616. [CrossRef]

24. Yao, J.; Ma, C.; He, W.P. Investor herding behaviour of Chinese stock market. Int. Rev. Econ. Financ. 2014, 29, 12-29. [CrossRef]

25. Gleason, K.C.; Mathur, I.; Peterson, M.A. Analysis of intraday herding behaviour among the sector ETFs. J. Empir. Financ. 2004, 11, 681-694. [CrossRef]

26. Pagan, A.R.; Sossounov, K.A. A simple framework for analyzing bull and bear markets. J. Appl. Econ. 2003, 18, 23-46. [CrossRef] 
27. Brown, G.W.; Cliff, M.T. Investor sentiment and the near-term stock market. J. Empir. Financ. 2004, 11, 1-27. [CrossRef]

28. Mobarek, A.; Mollah, S.; Keasey, K. A cross-country analysis of herd behaviour in Europe. J. Int. Financ. Mark. Inst. Money 2014, 32, 107-127. [CrossRef]

29. Abolafia, M.Y.; Kilduff, M. Enacting market crisis: The social construction of a speculative bubble. Adm. Sci. Q. 1988, 33, 177-193. [CrossRef]

30. Drożdż, S.; Grümmer, F.; Górski, A.Z.; Ruf, F.; Speth, J. Dynamics of competition between collectivity and noise in the stock market. Phys. A Stat. Mech. Appl. 2000, 287, 440-449. [CrossRef]

31. McQueen, G.; Pinegar, M.; Thorley, S. Delayed reaction to good news and the cross-autocorrelation of portfolio returns. J. Financ. 1996, 51, 889-919. [CrossRef]

32. Drożdż, S.; Grümmer, F.; Ruf, F.; Speth, J. Towards identifying the world stock market cross-correlations: DAX versus Dow Jones. Phys. A Stat. Mech. Appl. 2001, 294, 226-234. [CrossRef]

33. Lee, B.S.; Rui, O.M. The dynamic relationship between stock returns and trading volume: Domestic and cross-country evidence. J. Bank. Financ. 2002, 26, 51-78. [CrossRef]

34. Lao, P.; Singh, H. Herding behaviour in the Chinese and Indian stock markets. J. Asian Econ. 2011, 22, 495-506. [CrossRef]

35. Chiang, T.C.; Zheng, D. An empirical analysis of herd behaviour in global stock markets. J. Bank. Financ. 2010, 34, 1911-1921. [CrossRef]

36. Newey, W.K.; West, K. A simple positive semi-definite, heteroskedasticity and autocorrelation consistent covariance matrix. Econometrica 1987, 55, 703-708. [CrossRef]

37. Nofsinger, J.R.; Sias, R.W. Herding and feedback trading by institutional and individual investors. J. Financ. 1999, 54, 2263-2295. [CrossRef]

38. Koutmos, G. Positive feedback trading: A review. Rev. Behav. Financ. 2014, 6, 155-162. [CrossRef]

39. Jansen, D.W.; Tsai, C.L. Monetary policy and stock returns: Financing constraints and asymmetries in bull and bear markets. J. Empir. Financ. 2010, 17, 981-990. [CrossRef]

40. Kurov, A. Investor sentiment and the stock market's reaction to monetary policy. J. Bank. Financ. 2010, 34, 139-149. [CrossRef]

41. Vieito, J.P.; Wong, W.-K.; Zhu, Z.Z. Could the global financial crisis improve the performance of the G7 stocks markets? Appl. Econ. 2016, 48, 1066-1080. [CrossRef]

42. Wong, W.-K.; Manzur, M.; Chew, B.K. How rewarding is technical analysis? Evidence from Singapore stock market. Appl. Financ. Econ. 2003, 13, 543-551. [CrossRef] 